\title{
Indomethacin and disodium etidronate for the prevention of recurrence of heterotopic ossification after surgical resection. Two case reports
}

\author{
F Biering-Sørensen MD PhD, E Tøndevold MD PhD \\ Centre for Spinal Cord Injured, Department TH and Department of Orthopedic Surgery \\ U, Rigshospitalet, National University Hospital, Copenhagen, Denmark.
}

Two spinal cord injured patients had extensive heterotopic ossifications around their hips surgically removed. The use of disodium etidronate from 2 weeks presurgery to 2-5 months postsurgery and in particular indomethacin $25 \mathrm{mg}$ twice daily, from 2 weeks prior to surgery to 6 weeks postsurgery may have helped to prevent recurrence of the ossifications in the follow up periods of 4 and 5 years respectively.

Keywords: spinal cord injury; heterotopic ossification; surgery; disodium etidronate; indomethacin.

\section{Introduction}

The incidence of heterotopic ossification (HO) in patients with spinal cord injuries (SCI) according to the literature is between $8 \%$ and $25 \%,{ }^{1-7}$ and approximately one third of the affected patients develop restricted range of motion in the hip(s), ${ }^{1,6}$ which may compromise activities of daily living, especially dressing, and impair sitting. ${ }^{4,8}$

Resection of $\mathrm{HO}$ is often followed by bony recurrence. ${ }^{8}$ Some studies indicate that treatment with diphosphonates/disodium etidronate pre- and postoperatively may reduce the recurrence of ossification after surgery in SCI. ${ }^{8-10}$ In recent years indomethacin has been shown to be able to prevent heterotopic bone formation following total hip arthroplasty, and appears to be valuable as a supplement to secondary excision. ${ }^{11-14}$

Because we have experienced promising results in 2 patients operated on for extensive $\mathrm{HO}$ using disodium etidronate and indomethacin pre- and postoperatively, we have found it worthwhile to report the case histories.

Correspondence: Fin Biering-Sørensen, Centre for Spinal Cord Injured, National University Hospital, Rigshospital, Havnevej 25, DK-3100 Hornbæk, Denmark.

\section{Case 1}

A 23 year old man sustained during military training fractures of vertebrae $\mathrm{C} 5$ and $\mathrm{C} 6$, with a C6 motor complete and sensory incomplete lesion. Two and a half months postinjury there was increased circumference of the thigh on the right side, the serum alkaline phosphatase (SAP) was elevated, and xray showed ossifications at the level of the lesser trochanter of the right femur. Eight months postinjury xrays showed bilateral ossifications around the femoral neck and trochanter regions measuring approximately $20 \times 7 \mathrm{~cm}$. Twenty months postinjury hip flexion was reduced to approximately $40^{\circ}$ bilaterally making transfers, eg into his car, difficult. Three and a half years postinjury SAP was normal, but a bone scintigram (BS) showed increased uptake around both hips. Six and one sixth years post injury BS appearance was almost unchanged, and the ossifications were removed without surgical complications using the Watson-Jones approach bilaterally in a one stage operation. The patient was treated with disodium etidronate beginning 2 weeks presurgery to 3 months postsurgery with a dose of $20 \mathrm{mg}$ per $\mathrm{kg}$ body weight per day: in the 4th month postsurgery he was given $10 \mathrm{mg}$ per $\mathrm{kg}$ per day, and in the 5th month postsurgery $5 \mathrm{mg}$ per $\mathrm{kg}$ per day. In addition he was given indomethacin $25 \mathrm{mg}$ twice daily, from 2 weeks prior to surgery to 6 weeks postsurgery. After the operation he had passive exercises for the lower limbs with full ranges of movement, which in the hips corresponded to flexion of $105^{\circ}$ on the right and $115^{\circ}$ on the left side. 
Three months after the operation the range of movement was unchanged, and the patient could now manage transfers to/from bed/toilet/ wheelchair/car, and could more easily dress himself. Five years after surgery the range of movement in the hips was unchanged.

\section{Case 2}

A Somalian refugee came to Denmark at the age of 20 years. At the age of 16 years he fell in a bathroom. Four months later, an xray showed fractures of the T2, T4, T6 and T7 vertebrae, and there were no reported neurological deficits at this time. He then had treatment with traction and, in relation to this, pareses of both lower limbs developed. A laminectomy of $\mathrm{T} 7$ was performed 9 months after the initial injury, but with no change in the neurological situation.

When first seen in our centre he was found to have a motor and sensory incomplete $\mathrm{T} 4$ spinal cord lesion. Xrays revealed marked halisteresis in the trochanter regions and large ossifications around both hips and along the femoral shafts corresponding to a range of flexion movement of $35^{\circ}$ and $20^{\circ}$ on right and left side respectively. The patient's sitting position was very difficult, and he could not wash his feet or put on socks or shoes. The SAP was elevated, and a BS showed increased activity around both hips, and at the proximal parts of the femoral shafts. Two years later the xray and BS findings were unchanged, but the SAP was nearly normal. The ossifications were removed through a bilateral Watson-Jones approach. The same pre- and postoperative treatment with disodium etidronate and indomethacin as reported in case 1 was initiated. The passive range of movement of flexion of the hips 2 weeks after the operation was on the right and left side $90^{\circ}$ and $85^{\circ}$ respectively. After the operation the SAP increased. Nearly 2 months postsurgery it was found that during rehabilitation, including standing, the patient had an undislocated pertrochanteric stress fracture at the left side. Internal fixation with a dynamic hip screw was performed. Because of the fracture and the halisteretic bones it was decided not to treat the patient further with disodium etidronate. Three months later the SAP became normal, and hip flexion was $90^{\circ}$ bilaterally, which meant that his sitting position had considerably improved. After discharge he was even able to participate in wheelchair basketball. Four years after the excision there were no changes in the flexion ability of the hips and his activities of daily living were still considerably better than they were before the resection.

\section{Discussion}

According to Garland \& Orwin ${ }^{8}$ the greatest reduction in motion occurred within the first 6 months after surgery. Thus our 2 patients appeared to have managed very well.

Even although the optimal timing of surgical resection of $\mathrm{HO}$ is still uncertain, ${ }^{15}$ we decided to await normal SAP and stable BS before surgery as previously indicated. ${ }^{4,16,17}$

In the hope of reducing the risk of recurrence ${ }^{15}$ we used disodium etidronate $^{8-10,18,19}$ as well as indomethacin ${ }^{11-14,20}$ pre- and postoperatively. In addition, we used an aggressive programme of passive range of motion exercises ${ }^{21-22}$ immediately postsurgery and maintained movements during subsequent months. ${ }^{17}$

Our experience with a patient developing a femoral fracture in the postoperative period may not be unexpected ${ }^{8,15,17}$ because of the presence of disuse osteoporosis, together with the treatment with disodium etidronate. Even after discontinuation of etidronate and in spite of the fracture the patient had a very satisfactory functional outcome. Whether this result can be attributed to the effect of indomethacin is of course not possible to judge from our very limited experience, and as stated by others $^{13,15,17,23}$ further research is required in this area to prove or disprove the value of nonsteroidal antiinflammatory drugs, such as indomethacin, in the prophylaxis of $\mathrm{HO}$ both in the initial period after a spinal cord injury and after the surgical resection of $\mathrm{HO}$.

\section{References}

1 Blane CE, Perkash I (1981) True heterotopic bone in the paralyzed patient. Skeletal Radiol 7: 21-25.

2 Hsu JD, Sakimura I, Stauffer ES (1975) Heterotopic ossification around the hip joint in spinal cord injured patients. Clin Orthop 112: 165-169. 
3 Knudsen L, Lundberg D, Ericsson G (1982) Myositis ossificans circumscripta in para-/tetraplegics. Scand J Rheumatol 11: 27-31.

4 Tibone J, Sakimura I, Nickel VL, Hsu JD (1978) Heterotopic ossification around the hip in spinal cord-injured patients. A long-term follow-up study. J Bone Joint Surg 60A: 769-775.

5 Venier LH, Ditunno JF (1971) Heterotopic ossification in the paraplegic patient. Arch Phys Med Rehabil 52: $475-479$.

6 Wharton GW (1975) Heterotopic ossification. Clin Orthop 112: 142-149.

7 Wittenberg RH, Peschke U, Bötel U (1992) Heterotopic ossification after spinal cord injury. J Bone Joint Surg 74B: $215-218$

8 Garland DE, Orwin JF (1989) Resection of heterotopic ossification in patients with spinal cord injuries. Clin Orthop 242: 169-176.

9 Lindholm TS, Bauer FCH, Rindell K (1987) High doses of the diphosphonate EHDP for the prevention of heterotopic ossification. An experimental and clinical study. Scand J Rheumatol 16: 33-39.

10 Stover SL, Niemann KMW, Miller III JM (1976) Disodium etidronate in the prevention of postoperative recurrence of heterotopic ossification in spinal-cord injury patients. J Bone Joint Surg 58A: 683-688.

11 Kjærsgaard-Andersen P, Schmidt SA (1986) Indomethacin for prevention of ectopic ossification after hip arthroplasty. Acta Orthop Scand 57: 12-14.

12 Ritter MA, Sieber JM (1985) Prophylactic indomethacin for the prevention of heterotopic bone formation following total hip arthroplasty. Clin Orthop 196: 217-225.

13 Sawyer JR, Myers MA, Rosier RN, Puzas LE (1991) Heterotopic ossification: Clinical and cellular aspects. Calcif Tissue Int 49: 208-215.

14 Schmidt SA, Kjærsgaard-Andersen P, Pedersen NW, Kristensen SS, Pedersen P, Nielsen JB (1988) The use of indomethacin to prevent the formation of heterotopic bone after total hip replacement. A randomized, double-blind clinical trial. J Bone Joint Surg 70A: 834-838.

15 Stover SL, Niemann KMW, Tulloss JR (1991) Experience with surgical resection of heterotopic bone in spinal cord injury patients. Clin Orthop 263: 71-79.

16 Chantraine A, Minaire P (1981) Para-osteo-arthropathies. A new therapy and mode of treatment. Scand J Rehabil Med 13: 31-37.

17 Garland DE (1991) A clinical perspective on common forms of acquired heterotopic ossification. Clin Orthop 263: 13-29.

18 Freed JH, Hahn H, Menter R, Dillon T (1982) The use of the three-phase bone scan in the early diagnosis of heterotopic ossification (HO) and in the evaluation of didronel therapy. Paraplegia 20: 208-216.

19 Garland DE, Alday B, Venos KG, Vogt JC (1983) Diphosphonate treatment for heterotopic ossification in spinal cord injury patients. Clin Orthop 176: 197-200.

20 Ritter MA, Gide TJ (1982) The effect of indomethacin on para-articular ectopic ossification following total hip arthropathy. Clin Orthop 167: 113-117.

21 Garland DE, Razza BE, Waters RL (1982) Forceful joint manipulation in head-injured adults with heterotopic ossification. Clin Orthop 169: 133-138.

22 Stover SL, Hataway CJ, Zeiger HE (1975) Heterotopic ossification in spinal cord-injured patients. Arch Phys Med Rehabil 56: 199-204.

23 Glenn MB (1988) Pharmacological treatment of heterotopic ossification. J Head Trauma Rehabil 3: 86-89. 